\title{
Role of Respiratory Drive in Hyperoxia-Induced Hypercapnia in Ready-to-Wean Subjects With COPD
}

\author{
Gemma Rialp MD, Joan M Raurich MD, Juan A Llompart-Pou MD, and Ignacio Ayestarán MD
}

\begin{abstract}
BACKGROUND: Hyperoxia-induced hypercapnia in subjects with COPD is mainly explained by alterations in the ventilation/perfusion ratio. However, it is unclear why respiratory drive does not prevent $\mathrm{CO}_{2}$ retention. Some authors have highlighted the importance of respiratory drive in $\mathrm{CO}_{2}$ increases during hyperoxia. The aim of the study was to examine the effects of hyperoxia on respiratory drive in subjects with COPD. METHODS: Fourteen intubated, ready-to-wean subjects with COPD were studied during normoxia and hyperoxia. $\mathrm{A} \mathrm{CO}_{2}$ response test was then performed with the rebreathing method to measure the hypercapnic drive response, defined as the ratio of change in airway-occlusion pressure $0.1 \mathrm{~s}$ after the start of inspiratory flow $\left(\Delta \mathbf{P}_{0.1}\right)$ to change in $\mathbf{P}_{\mathrm{aCO}_{2}}\left(\Delta \mathbf{P}_{\mathrm{aCO}_{2}}\right)$, and the hypercapnic ventilatory response, defined as the ratio of change in minute volume $\left(\Delta \dot{V}_{E}\right)$ to $\Delta P_{\mathrm{aCO}_{2}}$. RESULTS: Hyperoxia produced a significant increase in $\mathrm{P}_{\mathrm{aCO}_{2}}(55 \pm 9 \mathrm{vs}$ $58 \pm 10 \mathrm{~mm} \mathrm{Hg}, P=.02)$ and a decrease in $\mathrm{pH}(7.41 \pm 0.05$ vs $7.38 \pm 0.05, P=.01)$ compared with normoxia, with a non-significant decrease in $\dot{\mathrm{V}}_{\mathrm{E}}(9.9 \pm 2.9$ vs $9.1 \pm 2.3 \mathrm{~L} / \mathrm{min}, P=.16)$ and no changes in $P_{0.1}\left(2.85 \pm 1.40\right.$ vs $\left.2.82 \pm 1.16 \mathrm{~cm} \mathrm{H}_{2} \mathrm{O}, P=.97\right)$ The correlation between hyperoxia-induced changes in $\dot{\mathrm{V}}_{\mathrm{E}}$ and $\mathrm{P}_{\mathrm{aCO}}$ was $\mathrm{r}^{2}=0.38(P=.02)$. Median $\Delta \mathrm{P}_{0.1} / \Delta \mathrm{P}_{\mathrm{aCO}}$ and $\Delta \dot{\mathrm{V}}_{\mathrm{E}} / \Delta \mathrm{P}_{\mathrm{aCO}_{2}}$ did not show significant differences between normoxia and hyperoxia: $0.22(0.12-$ $0.49) \mathrm{cm} \mathrm{H}_{2} \mathrm{O} / \mathrm{mm} \mathrm{Hg}$ versus $0.25(0.14-0.34) \mathrm{cm} \mathrm{H}_{2} \mathrm{O} / \mathrm{mm} \mathrm{Hg}(P=.30)$ and $0.37(0.12-0.54)$ $\mathrm{L} / \mathrm{min} / \mathrm{mm} \mathrm{Hg}$ versus $0.35(0.12-0.96) \mathrm{L} / \mathrm{min} / \mathrm{mm} \mathrm{Hg}(P=.20)$, respectively. CONCLUSIONS: In ready-to-wean subjects with COPD exacerbations, hyperoxia is followed by an increase in $\mathrm{P}_{\mathrm{aCO}}$, but it does not significantly modify the respiratory drive or the ventilatory response to hypercapnia. Key words: hyperoxia; COPD; respiratory center; artificial respiration; hypercapnia/physiopathology; $P_{\text {o.l }}$; reproducibility. [Respir Care 2015;60(3):328-334. (C) 2015 Daedalus Enterprises]
\end{abstract}

\section{Introduction}

Breathing high concentrations of oxygen may result in hypercapnia in subjects with COPD. Historically, the increased $\mathrm{P}_{\mathrm{aCO}}$ resulting from oxygen administration in subjects with COPD was attributed to the oxygen-induced

Dr Rialp is affiliated with the Intensive Care Unit, Hospital Son Llàtzer, Palma de Mallorca, Spain. Drs Raurich, Llompart-Pou, and Ayestarán are affiliated with the Intensive Care Unit, Hospital Universitari Son Espases, Palma de Mallorca, Spain.

The authors has disclosed no conflicts of interest.

Correspondence: Joan M Raurich MD, Servei de Medicina Intensiva, Hospital Universitari Son Espases, Carretera Valldemossa 79, 07010 Palma de Mallorca, Illes Balears, Spain. E-mail: joan.raurich@ssib.es.

DOI: $10.4187 /$ respcare. 03270 suppression of the hypoxic drive to breathe, with a consequent decrease in minute volume $\left(\dot{\mathrm{V}}_{\mathrm{E}}\right)$. However, no strong data support this hypothesis. ${ }^{1,2}$

From 1980 onward, several studies investigated the mechanisms by which hyperoxia induces hypercapnia in subjects with COPD. ${ }^{3-10}$ Most of these studies were conducted in non-intubated subjects with COPD through a mouthpiece, either in stable ${ }^{5,8}$ or unstable ${ }^{3,4,6}$ respiratory conditions. Most concluded that the control of ventilation played a minor role and suggested that the main mechanism to impair gas exchange during hyperoxia was a release of hypoxic pulmonary vasoconstriction that induced changes in the ventilation-perfusion distribution and entailed an increase in the dead-space-to-tidal-volume $\left(\mathrm{V}_{\mathrm{T}}\right)$ ratio. However, it was uncertain why the respiratory drive did not prevent this $\mathrm{CO}_{2}$ retention by increasing $\dot{\mathrm{V}}_{\mathrm{E}}$.

Although demonstrating an increase in dead space with hyperoxia in intubated subjects with COPD, Dunn et $\mathrm{al}^{7}$ 
identified alteration of respiratory drive during hyperoxia as an important mechanism in the pathogenesis of hypercapnia in subjects with COPD. Moreover, again with intubated, ready-to-wean subjects utilizing pressure support ventilation (PSV), Crossley et al ${ }^{11}$ found no differences in $\mathrm{P}_{\mathrm{aCO}_{2}}$ after hyperoxia in $\mathrm{CO}_{2}$-retaining subjects with COPD. Robinson et $\mathrm{al}^{6}$ studied ventilation-perfusion distribution in non-intubated subjects with COPD; they observed different responses to hyperoxia (some subjects experienced hypercapnia and others did not) and attributed hypercapnia to a reduction of overall ventilation rather than a redistribution of blood flow.

\section{See the Related Editorial on Page 473}

In clinical practice, during the weaning period from mechanical ventilation, normoxia is the standard target in subjects with COPD. In this context and compared with hypoxia, the contribution of the release of hypoxic pulmonary vasoconstriction to the development of hyperoxiainduced hypercapnia should be reduced, and the role of respiratory drive could become more important.

Respiratory drive may be assessed through the negative pressure generated $100 \mathrm{~ms}$ after the onset of an occluded inspiration $\left(\mathrm{P}_{0.1}\right) . \mathrm{P}_{0.1}$ is widely accepted as an index of respiratory drive performance, ${ }^{12}$ although it may be affected by drugs, gas exchange, respiratory muscle function, ${ }^{13}$ or lung volume. It is important to note that variations in $\mathrm{P}_{\mathrm{aCO}_{2}}$ observed with hyperoxia in subjects with COPD may be not wide enough to produce a measurable change in $\mathrm{P}_{0.1}{ }^{5,7,11} \mathrm{~A} \mathrm{CO}_{2}$ response test, which increases $\mathrm{P}_{\mathrm{aCO}_{2}}$ by $>10 \mathrm{~mm} \mathrm{Hg}$, may thus be a reliable method to compare the respiratory drive performance in normoxia and hyperoxia. However, there is an inherent variability in the measurement of the $\mathrm{CO}_{2}$ response test ${ }^{14,15}$ that can mislead the interpretation of small differences between normoxia and hyperoxia.

The aim of this investigation was to assess the influence of the central respiratory drive on the hyperoxia-induced hypercapnia that occurs in normoxic, intubated, ready-towean subjects with COPD. For this purpose, we compared respiratory physiologic parameters, including the results of the $\mathrm{CO}_{2}$ response test, in normoxia and hyperoxia. Previously and according to the described variability of these measurements, we performed a reproducibility analysis of the $\mathrm{CO}_{2}$ response.

\section{Methods}

\section{Subjects}

To analyze the reproducibility of the $\mathrm{CO}_{2}$ response test, we prospectively studied 30 subjects connected to me-

\section{QUICK LOOK}

\section{Current knowledge}

Hyperoxia-induced hypercapnia in patients with COPD is attributed to alterations in ventilation/perfusion ratio, not an alteration in respiratory drive. However, it is unclear why respiratory drive does not prevent carbon dioxide retention.

\section{What this paper contributes to our knowledge}

In normoxic subjects with COPD requiring mechanical ventilation, at the time of weaning, hyperoxia does not seem to modify the central respiratory drive or the ventilatory response to hypercapnia. Hyperoxia is followed by a slight increase in $\mathrm{P}_{\mathrm{aCO}}$, possibly due to alterations in ventilation/perfusion matching and the Haldane effect.

chanical ventilation and ready to wean. To study the effects of hyperoxia, we prospectively studied 14 intubated subjects with COPD exacerbations who were recovering from acute respiratory failure and who fulfilled clinical criteria for a spontaneous breathing test. ${ }^{16}$ All subjects were free of sedatives, awake, and able to obey commands. Informed consent was obtained from subjects or their closest relatives. The study had the approval of the institutional review board.

\section{Study Protocol}

Electrocardiogram, heart rate, pulse oximetry, invasive systemic blood pressure, and capnography (Capnostat $\mathrm{CO}_{2}$ sensor, Marquette, Milwaukee, Wisconsin) were continuously monitored during the study. Pulmonary function measurements were carried out with the subject in a semirecumbent position and after endotracheal suctioning.

All subjects were studied twice by the same investigator. For the reproducibility analysis, we performed the 2 repeated studies with an $\mathrm{F}_{\mathrm{IO}_{2}}$ of 1. For the hyperoxia analysis, we performed the studies in normoxia and hyperoxia, with a crossover design in a random order. Normoxia was achieved by adjusting the $\mathrm{F}_{\mathrm{IO}_{2}}$ to reach an $\mathrm{S}_{\mathrm{pO}_{2}}$ of $89-94 \%$. Hyperoxia was established with an $\mathrm{F}_{\mathrm{IO}_{2}}$ of 1 for all subjects.

\section{$\mathrm{CO}_{2}$ Response Test}

We followed the same methodology to perform the $\mathrm{CO}_{2}$ response test in both the reproducibility and COPD groups of subjects. The $\mathrm{CO}_{2}$ response test consisted of 2 sets of repeated measurements, first at baseline and then after reaching hypercapnia. Each $\mathrm{CO}_{2}$ test lasted $\sim 30 \mathrm{~min}$. 


\section{RESPIRATORY DRIVE AND HyPEROXIA-INDUCED HyPERCAPNIA}

Thirty min before the start of measurements, we adjusted the $\mathrm{F}_{\mathrm{IO}_{2}}$ as defined by the study protocol. Fifteen min later, we set PSV mode with a pressure support of $7 \mathrm{~cm} \mathrm{H}_{2} \mathrm{O}$ and no PEEP. At the start of the measurements, $\dot{\mathrm{V}}_{\mathrm{E}}$, breathing frequency, and $\mathrm{P}_{0.1}$ were recorded from the ventilator display (Evita 2 Dura or Evita 4, Dräger, Lübeck, Germany), and an arterial blood sample was drawn. While maintaining the subject breathing with PSV of $7 \mathrm{~cm} \mathrm{H}_{2} \mathrm{O}$, we used the method of re-inhalation of expired air to reach hypercapnia ${ }^{17-19}$ by inserting a corrugated tube between the Y-piece and the endotracheal tube, which increased the dead space, ${ }^{17,18}$ by a volume similar to the $\mathrm{V}_{\mathrm{T}}$ obtained with a pressure support of $7 \mathrm{~cm} \mathrm{H}_{2} \mathrm{O}$. After at least 4 min of rebreathing and until exhaled $\mathrm{CO}_{2}$ had increased by almost $10 \mathrm{~mm} \mathrm{Hg}$ and remained constant, we again measured $\dot{\mathrm{V}}_{\mathrm{E}}$, breathing frequency, and $\mathrm{P}_{0.1}$ and took another arterial blood sample. Once the $\mathrm{CO}_{2}$ response test was finished, the added dead space was removed, and the subject was returned to the original ventilatory settings. A second $\mathrm{CO}_{2}$ response test was repeated by the same investigator $1 \mathrm{~h}$ after finishing the first study with the $\mathrm{F}_{\mathrm{IO}_{2}}$ adjusted according to the study protocol.

\section{Measurements and Procedures}

$\mathrm{P}_{0.1}$ values were measured with the ventilator's built-in system, ${ }^{20}$ and $\mathrm{P}_{0.1}$ was calculated as the mean of 5 measurements at each point of the study. ${ }^{21}$ Arterial blood gases were measured with a blood gas analyzer (IL-1650, Instrument Laboratory, Izasa, Spain).

We studied the following derived indexes: $\Delta \dot{\mathrm{V}}_{\mathrm{E}} / \Delta \mathrm{P}_{\mathrm{aCO}_{2}}$, which reflected the ventilatory response to hypercapnia and was calculated as the ratio of change in $\dot{V}_{\mathrm{E}}$ to change in $\mathrm{P}_{\mathrm{aCO}_{2}}$; and $\Delta \mathrm{P}_{0.1} / \Delta \mathrm{P}_{\mathrm{aCO}}$, which reflected the central drive response to hypercapnia and was calculated as the ratio of change in $\mathrm{P}_{0.1}$ to change in $\mathrm{P}_{\mathrm{aCO}}$. The changes in $\dot{\mathrm{V}}_{\mathrm{E}}, \mathrm{P}_{0.1}$, and $\mathrm{P}_{\mathrm{aCO}_{2}}$ were determined as the difference between the value at the end of the hypercapnia test and the baseline value.

\section{Statistical Analysis}

To analyze the reproducibility of the $\mathrm{CO}_{2}$ response test, we calculated the intraclass correlation coefficient (ICC) of consistency and agreement by analysis of variance. Differences in continuous variables between normoxia and hyperoxia were analyzed using the non-parametric Wilcoxon test for paired observations. Correlations between variables were explored using Pearson linear regression analysis. $P$ values $<.05$ were considered significant. Continuous data were expressed as mean \pm SD unless specified otherwise. Statistical analysis was performed with specific statistics software (SPSS 19.0, SPSS, Chicago, Illinois).
Table 1. Demographic and Clinical Characteristics of the 30 Subjects Included in the Reproducibility Analysis

\begin{tabular}{lc}
\hline \hline \multicolumn{1}{c}{ Characteristic } & Values \\
\hline Age (mean $\pm \mathrm{SD}), \mathrm{y}$ & $68 \pm 10$ \\
Males, $n(\%)$ & $17(57)$ \\
Weight (mean $\pm \mathrm{SD}), \mathrm{kg}$ & $73 \pm 16$ \\
Height (mean $\pm \mathrm{SD}), \mathrm{cm}$ & $164 \pm 12$ \\
SAPS II score (mean $\pm \mathrm{SD}$ ) & $41 \pm 11$ \\
Duration of mechanical ventilation before study, d* & $6(2-5)$ \\
& \\
* Median (interquartile range) & \\
SAPS II = Simplified Acute Physiology Score II & \\
\hline
\end{tabular}

\section{Results}

\section{Reproducibility Analysis of the $\mathrm{CO}_{2}$ Response Test}

Demographic and clinical characteristics of the 30 subjects included in this analysis are provided in Table 1 . The reproducibility test for $\Delta \mathrm{P}_{0.1} / \Delta \mathrm{P}_{\mathrm{aCO}}$ showed an ICC of consistency of 0.73 (95\% CI $0.51-0.86$ ) and an ICC of agreement of 0.76 (95\% CI 0.51-0.87), showing a good correlation between the 2 measurements, with a bias between measurements of $0.015 \mathrm{~cm} \mathrm{H}_{2} \mathrm{O} / \mathrm{mm} \mathrm{Hg}(P=.69)$. For $\Delta \dot{\mathrm{V}}_{\mathrm{E}} / \Delta \mathrm{P}_{\mathrm{aCO}_{2}}$, the reliability test showed an ICC of consistency of 0.87 (95\% CI $0.74-0.94)$ and an ICC of agreement of 0.86 (95\% CI 0.72-0.93), showing an excellent correlation between the 2 measurements, with a bias between measurements of $0.068 \mathrm{~L} / \mathrm{min} / \mathrm{mm} \mathrm{Hg}$ $(P=.06)$.

\section{Effects of Hyperoxia}

Fourteen subjects with COPD (12 men) were studied. Demographic and clinical characteristics are presented in Table 2 .

Table 2. Demographic and Clinical Characteristics of 14 Subjects With COPD Who Were Included in the Analysis of the Effects of Hyperoxia

\begin{tabular}{|c|c|}
\hline Characteristic & Values \\
\hline Age $($ mean $\pm S D), y$ & $65 \pm 8$ \\
\hline Weight (mean $\pm \mathrm{SD}), \mathrm{kg}$ & $88 \pm 27$ \\
\hline Height (mean $\pm \mathrm{SD}), \mathrm{cm}$ & $164 \pm 8$ \\
\hline SAPS II score (mean $\pm \mathrm{SD})$ & $38 \pm 11$ \\
\hline $\mathrm{FEV}_{1}($ mean $\pm \mathrm{SD}), \%$ predicted $*$ & $40 \pm 18$ \\
\hline $\mathrm{FEV}_{1} / \mathrm{FVC}($ mean $\pm \mathrm{SD}), \%$ predicted $*$ & $58 \pm 17$ \\
\hline Duration of mechanical ventilation before study, $\mathrm{d} \dagger$ & $3(2-4)$ \\
\hline $\begin{array}{l}\text { * Measurements available in } 12 \text { subjects. } \\
\dagger \text { Median (interquartile range) } \\
\text { SAPS II = Simplified Acute Physiology Score II }\end{array}$ & \\
\hline
\end{tabular}



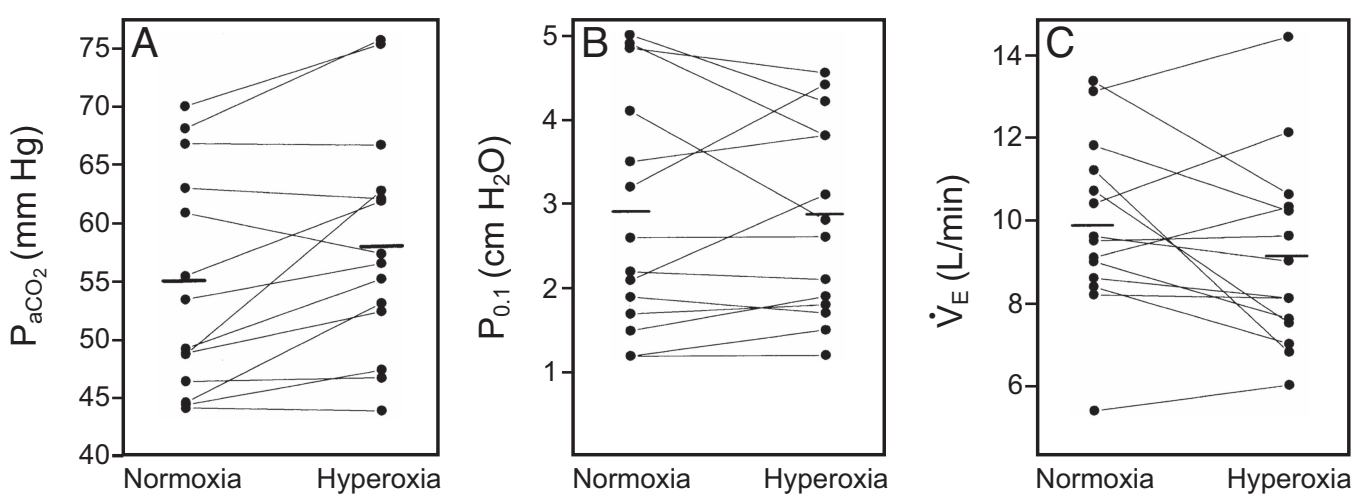

Fig. 1. Individual and mean (indicated by horizontal lines) baseline values of $\mathrm{P}_{\mathrm{aco}}(P=.02)(\mathrm{A})$, airway-occlusion pressure $0.1 \mathrm{~s}$ after the start of inspiratory flow $\left(\mathrm{P}_{0.1} ; P=.97\right)(\mathrm{B})$, and minute volume $\left(\dot{\mathrm{V}}_{\mathrm{E}} ; P=.10\right)(\mathrm{C})$ in normoxia and hyperoxia.

\section{Effect of Hyperoxia on Physiologic Variables}

Hyperoxia induced a significant increase in $\mathrm{P}_{\mathrm{aCO}_{2}}$, $\mathrm{P}_{\mathrm{aO}_{2}}$, and mean blood pressure and a decrease in $\mathrm{pH}$ and heart rate compared with normoxia, together with a non-significant decrease in $\dot{\mathrm{V}}_{\mathrm{E}}$ and no changes in $\mathrm{P}_{0.1}$ (Table 3). Individual baseline values of $\mathrm{P}_{\mathrm{aCO}}, \mathrm{P}_{0.1}$, and $\dot{\mathrm{V}}_{\mathrm{E}}$ in normoxia and hyperoxia are shown in Figure 1.

Changes in $\dot{\mathrm{V}}_{\mathrm{E}}$ induced by hyperoxia showed a weak correlation with the increase in $\mathrm{P}_{\mathrm{aCO}_{2}}$ induced by hyperoxia $\left(\mathrm{r}^{2}=0.38, P=.02\right)$ (Fig. 2$)$, and no association was

Table 3. Baseline Physiologic Characteristics and $\mathrm{CO}_{2}$ Response in Normoxia and Hyperoxia in 14 COPD Subjects

\begin{tabular}{|c|c|c|c|}
\hline Characteristic & Normoxia & Hyperoxia & $P$ \\
\hline $\mathrm{pH}($ mean $\pm \mathrm{SD})$ & $7.41 \pm 0.05$ & $7.38 \pm 0.05$ & .01 \\
\hline $\mathrm{P}_{\mathrm{aCO}_{2}}($ mean $\pm \mathrm{SD}), \mathrm{mm} \mathrm{Hg}$ & $55 \pm 9$ & $58 \pm 10$ & .02 \\
\hline $\mathrm{P}_{\mathrm{aO}_{2}}($ mean $\pm \mathrm{SD}), \mathrm{mm} \mathrm{Hg}$ & $66 \pm 4$ & $359 \pm 127$ & .001 \\
\hline $\mathrm{P}_{0.1}($ mean $\pm \mathrm{SD}), \mathrm{cm} \mathrm{H}_{2} \mathrm{O}$ & $2.85 \pm 1.40$ & $2.82 \pm 1.16$ & .97 \\
\hline$\dot{\mathrm{V}}_{\mathrm{E}}($ mean $\pm \mathrm{SD}), \mathrm{L} / \mathrm{min}$ & $9.9 \pm 2.9$ & $9.1 \pm 2.3$ & .16 \\
\hline $\begin{array}{l}\text { Breathing frequency, } \\
\text { breaths/min }\end{array}$ & $24 \pm 5$ & $23 \pm 5$ & .32 \\
\hline $\begin{array}{l}\text { Mean blood pressure } \\
\quad(\text { mean } \pm \mathrm{SD}), \mathrm{mm} \mathrm{Hg}\end{array}$ & $102 \pm 16$ & $107 \pm 14$ & .04 \\
\hline $\begin{array}{l}\text { Heart rate }(\text { mean } \pm S D), \\
\text { beats/min }\end{array}$ & $89 \pm 12$ & $83 \pm 11$ & .003 \\
\hline $\begin{array}{l}\Delta \mathrm{P}_{0.1} / \Delta \mathrm{P}_{\mathrm{aCO}_{2}} \\
\quad \mathrm{~cm} \mathrm{H} \mathrm{H}_{2} \mathrm{O} / \mathrm{mm} \mathrm{Hg}^{*}\end{array}$ & $0.22(0.12-0.49)$ & $0.25(0.14-0.34)$ & .30 \\
\hline $\begin{array}{l}\Delta \dot{\mathrm{V}}_{\mathrm{E}} / \Delta \mathrm{P}_{\mathrm{aCO}_{2}} \\
\quad \mathrm{~L} / \mathrm{min} / \mathrm{mm} \mathrm{Hg} *\end{array}$ & $0.37(0.12-0.54)$ & $0.35(0.12-0.96)$ & .20 \\
\hline \multicolumn{4}{|c|}{$\begin{array}{l}\text { * Median (interquartile range) } \\
\mathrm{P}_{0.1}=\text { airway-occlusion pressure } 0.1 \mathrm{~s} \text { after the start of inspiratory flow } \\
\mathrm{V}_{\mathrm{E}}=\text { minute volume }\end{array}$} \\
\hline
\end{tabular}

found between $\mathrm{FEV}_{1}$ and changes in $\mathrm{P}_{\mathrm{aCO}}$ induced by hyperoxia $\left(\mathrm{r}^{2}=0.13, P=.24\right)$.

\section{Effects of Hyperoxia in $\mathrm{CO}_{2}$ Response Test}

The $\mathrm{CO}_{2}$ response test in normoxia and hyperoxia did not show significant differences for both indexes studied $\left(\Delta \dot{\mathrm{V}}_{\mathrm{E}} / \Delta \mathrm{P}_{\mathrm{aCO}_{2}}\right.$ and $\left.\Delta \mathrm{P}_{0.1} / \Delta \mathrm{P}_{\mathrm{aCO}_{2}}\right)$ (see Table 3). Individual values are shown in Figure 3.

Changes in baseline $\mathrm{P}_{\mathrm{aCO}_{2}}$ in normoxia and hyperoxia were not associated with changes in $\Delta \mathrm{P}_{0.1} / \Delta \mathrm{P}_{\mathrm{aCO}_{2}}$ $\left(\mathrm{r}^{2}=0.02, P=.6\right)($ Fig. $4 \mathrm{~A})$ and had a weak correlation with changes in $\Delta \dot{\mathrm{V}}_{\mathrm{E}} / \Delta \mathrm{P}_{\mathrm{aCO}_{2}}\left(\mathrm{r}^{2}=0.43, P=.01\right)$ (Fig. 4B). According to COPD severity, $\Delta \dot{\mathrm{V}}_{\mathrm{E}} / \Delta \mathrm{P}_{\mathrm{aCO}_{2}}$ showed a positive correlation with $\mathrm{FEV}_{1}\left(\mathrm{r}^{2}=0.61\right.$, $P=.003)$ that was not observed with $\Delta \mathrm{P}_{0.1} / \Delta \mathrm{P}_{\mathrm{aCO}_{2}}$ $\left(\mathrm{r}^{2}=0.03, P=.58\right)$.

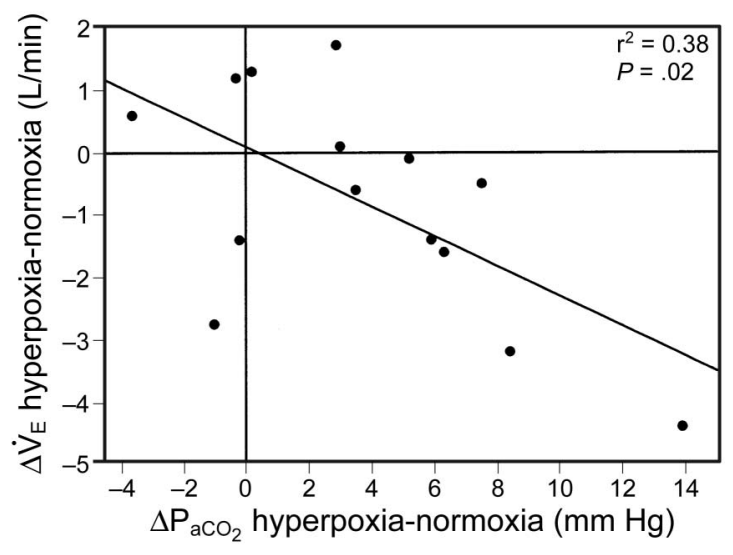

Fig. 2. Relationship between subject variations in $\mathrm{P}_{\mathrm{aCO}}$ and minute volume $\left(\dot{V}_{E}\right)$ induced by hyperoxia. 


\section{RESPIRATORY DRIVE AND HyPEROXIA-INDUCED HyPERCAPNIA}
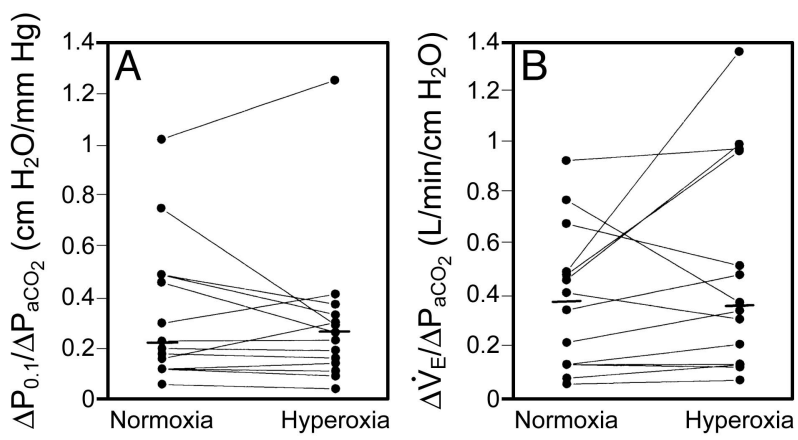

Fig. 3. Individual values and median of $\Delta \mathrm{P}_{0.1} / \Delta \mathrm{P}_{\mathrm{acO}}$ (where $\mathrm{P}_{0.1}$ is airway-occlusion pressure $0.1 \mathrm{~s}$ after the start of inspiratory flow) (A) and $\Delta \dot{\mathrm{V}}_{\mathrm{E}} / \Delta \mathrm{P}_{\mathrm{aCO}}$ (where $\dot{\mathrm{V}}_{\mathrm{E}}$ is minute volume) (B) in normoxia and hyperoxia.

\section{Discussion}

We focused on assessing the role of central respiratory drive in oxygen-induced hypercapnia observed in subjects with COPD. According to our results, the small but significant increase in $\mathrm{P}_{\mathrm{aCO}_{2}}$ induced by hyperoxia was not associated with a decrease in $\mathrm{P}_{0.1}$. Indeed, mean baseline $\mathrm{P}_{0.1}$ values were preserved and remained unaltered in our subjects. In accordance, although being reduced to some extent, $\Delta \mathrm{P}_{0.1} / \Delta \mathrm{P}_{\mathrm{aCO}_{2}}$ in hyperoxia did not change significantly compared with normoxia, as found in other studies. ${ }^{3,5,11}$ Our results suggest that an attenuation of respiratory drive functioning would not be the main mechanism to explain the hyperoxia-induced hypercapnia in normoxic, ready-to-wean subjects with COPD.

Nevertheless, there are some aspects that should be considered to carefully interpret these results. It should be noted that if the respiratory drive were intact, $\Delta \mathrm{P}_{0.1} / \Delta \mathrm{P}_{\mathrm{aCO}_{2}}$ should have been increased compared with normoxia because of the rise in $\mathrm{P}_{\mathrm{aCO}}$. Therefore, a possible blunted response of the respiratory drive cannot be totally ruled out.

PSV could have decreased or increased the work of breathing and $\mathrm{P}_{0.1}$ values depending on the amount of inspiratory assistance applied. ${ }^{22}$ Several studies found no differences in work of breathing ${ }^{23,24}$ or in $\mathrm{P}_{0.1}$ measurements ${ }^{24}$ during low levels of pressure support compared with T-piece breathing. In our study, if the level of pressure support applied had been low enough to entail an increase in $\mathrm{P}_{0.1}$ due to the additional work of breathing caused by the endotracheal tube and the circuit, it could have counterbalanced an eventual decrease in $\mathrm{P}_{0.1}$. Relative to $\dot{V}_{E}$, low levels of PSV may increase $V_{T}$ compared with T-piece breathing. ${ }^{23,24}$ However, as we applied the same ventilatory settings in normoxia and hyperoxia, it seems unlikely that this circumstance could significantly affect the comparison between the 2 conditions at baseline.

Hyperoxia induced in our subjects with COPD a nonsignificant decrease in $\dot{\mathrm{V}}_{\mathrm{E}}$ that was poorly correlated with changes in $\mathrm{P}_{\mathrm{aCO}}$. Other studies on subjects with $\mathrm{COPD}$ observed similar results. ${ }^{4,5}$ The hyperoxia-induced hypercapnia observed in these studies was assumed to result principally from an increase in the dead-space-to- $\mathrm{V}_{\mathrm{T}}$ ratio or from alterations in ventilation/perfusion matching rather than from a reduction in ventilation. ${ }^{4,5}$ Because dead space is sensitive to changes in $\mathrm{P}_{\mathrm{aCO}}$, the Haldane effect on $\mathrm{P}_{\mathrm{aCO}}$ might be responsible, in part, for the increase in dead space during hyperoxia. ${ }^{25}$ Interestingly and in accordance with these results, Santos et $\mathrm{al}^{10}$ observed an increase in $\mathrm{P}_{\mathrm{aCO}}$ of $4 \mathrm{~mm} \mathrm{Hg}$ while breathing $100 \%$ oxygen in 4 subjects with COPD connected to mechanical ventilation, sedated, and paralyzed, keeping $\dot{\mathrm{V}}_{\mathrm{E}}$ constant. The multiple inert gas elimination technique detected in these subjects an increase in the dispersion of blood flow distribution, suggesting a release of hypoxic pulmonary vasoconstriction as the main mechanism of hypercapnia. In
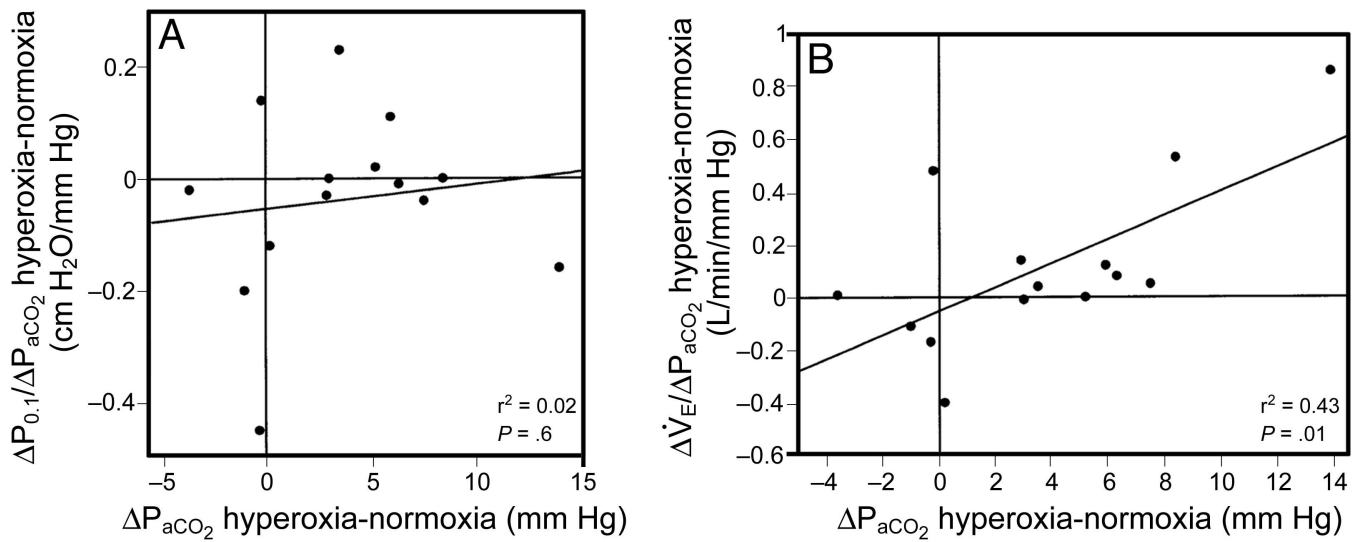

Fig. 4. Relationship between changes in baseline $\mathrm{P}_{\mathrm{acO}_{2}}$ induced by hyperoxia and the central drive response to hypercapnia $\left(\Delta \mathrm{P}_{0.1} / \Delta \mathrm{P}_{\mathrm{acO}}\right.$, where $P_{0.1}$ is airway-occlusion pressure $0.1 \mathrm{~s}$ after the start of inspiratory flow) $(\mathrm{A})$ and the ventilatory response to hypercapnia $\left(\Delta \dot{V}_{E} / \Delta \mathrm{P}_{a c O_{2}}\right.$, where $\dot{\mathrm{V}}_{\mathrm{E}}$ is minute volume) (B). 


\section{RESPIRATORY DRIVE AND HyPEROXIA-INDUCED HyPERCAPNIA}

these experimental conditions of sedation and muscle relaxation, the influence of hyperoxia on the central respiratory drive response or the ventilatory response was totally abolished, and likewise, hypercapnia appeared.

Another feature that should be considered to explain the low correlation between the decrease in $\dot{\mathrm{V}}_{\mathrm{E}}$ and the increase in $\mathrm{CO}_{2}$ is that the increase in $\mathrm{CO}_{2}$ may be partially equilibrated by a concomitant decrease in $\mathrm{CO}_{2}$ production. Certainly, there is a positive linear association between changes in $\mathrm{CO}_{2}$ production and changes in $\dot{\mathrm{V}}_{\mathrm{E}}{ }^{4,5}$ The decrease in $\dot{\mathrm{V}}_{\mathrm{E}}$ may entail a decrease in the work of breathing and, as a result, a decrease in oxygen consumption and $\mathrm{CO}_{2}$ production. ${ }^{5}$ This phenomenon could also explain why 5 of our 14 subjects showed unexpected changes in $\mathrm{P}_{\mathrm{aCO}_{2}}$ according to their changes in $\dot{\mathrm{V}}_{\mathrm{E}}$ (see Fig. 2). Unfortunately, we did not measure $\mathrm{CO}_{2}$ production to confirm this hypothesis.

Moreover, we cannot exclude the contribution of the release of the hypoxic stimulus mediated by peripheral chemoreceptors on the decrease in $\dot{\mathrm{V}}_{\mathrm{E}}$. Changes in $\dot{\mathrm{V}}_{\mathrm{E}}$ may be influenced by changes in oxygenation when $\mathrm{P}_{a O_{2}}$ is $<100 \mathrm{~mm} \mathrm{Hg}$. The mean $\mathrm{P}_{\mathrm{aO}}$ in our subjects in normoxia was $66 \mathrm{~mm} \mathrm{Hg}$, and therefore, a diminished hypoxic response could be involved in the decrease in $\dot{\mathrm{V}}_{\mathrm{E}}$ in our subjects. Unfortunately, we did not have the $\mathrm{P}_{\mathrm{aO}_{2}}$ of our subjects in stable condition. We assumed that they were normoxic because no subject needed home oxygen therapy. However, eventual individual differences with study baseline $\mathrm{P}_{\mathrm{aO}}$ could have altered subjects' respiratory drive.

The severity of airway obstruction did not appear to be correlated with the development of hyperoxia-induced hypercapnia in our subjects, as described previously.7,26 In contrast, Sassoon et $\mathrm{al}^{5}$ found a linear association between $\mathrm{FEV}_{1}$ and changes in $\mathrm{P}_{\mathrm{aCO}}$ with hyperoxia. These discrepancies may arise from the fact that our subjects were on mechanical ventilation with pressure support of $7 \mathrm{~cm} \mathrm{H}_{2} \mathrm{O}$ and were recovering from an exacerbation, whereas in the Sassoon study, 5 they were stable outpatients without respiratory assistance. However, our subjects showed a positive correlation between $\mathrm{FEV}_{1}$ and hyperoxia-induced changes in $\Delta \dot{\mathrm{V}}_{\mathrm{E}} / \Delta \mathrm{P}_{\mathrm{aCO}_{2}}$, indicating that airway obstruction severity may affect the ventilatory response to hypercapnia without affecting respiratory drive.

Our mean increase in $\mathrm{P}_{\mathrm{aCO}}$ with hyperoxia was $3 \mathrm{~mm} \mathrm{Hg}$, similar to that observed in other studies comparing normoxia and hyperoxia,, 5 whereas this increase was $>2$ fold when comparing hypoxia with hyperoxia. ${ }^{4,8}$ It is plausible that normoxia would reverse prior hypoxic pulmonary vasoconstriction, and further increases in $\mathrm{F}_{\mathrm{IO}_{2}}$ should cause only a small increase in $\mathrm{P}_{\mathrm{aCO}}$. In fact, studies comparing normoxia and hyperoxia showed that hypercapnia did not happen in ready-to-wean, $\mathrm{CO}_{2}$-retaining subjects with COPD. ${ }^{11}$ Thus, in intubated, ready-to-wean patients with COPD, if a significant increase in $\mathrm{P}_{\mathrm{aCO}_{2}} \mathrm{Oc}-$ curs, we should first think of other causes of acute hypercapnia, such as an increase in bronchospasm, the presence of fatigue, or the effect of sedatives rather than the effect of hyperoxia. In clinical practice, clinicians should try to keep patients with COPD in normoxia irrespective of their clinical status because, although discrete, hypercapnia occurs likewise.

Among the limitations of our study, we note the small sample size that confers small power to our results, with wide $\mathrm{SD}$ values principally in the $\mathrm{CO}_{2}$ response indexes studied. In addition, it is possible that larger changes in $\mathrm{P}_{\mathrm{aCO}_{2}}$ after breathing $\mathrm{O}_{2}$ are required to demonstrate a significant relationship between changes in $\mathrm{P}_{\mathrm{aCO}_{2}}$ and $\mathrm{CO}_{2}$ response indexes.

Another limitation of the study is the interpretation of the $\mathrm{CO}_{2}$ response test due to the differences in baseline $\mathrm{P}_{\mathrm{aCO}_{2}}$ in normoxia and hyperoxia. This baseline difference could modify the respiratory response to hypercapnia and could mislead the interpretation of our results. However, owing to the linearity of the response described in the $\mathrm{CO}_{2}$ response test, we think this would minimally affect our results.

The reliability of the $\mathrm{CO}_{2}$ response test may be another limitation of the study. As described previously, the variability of $\mathrm{CO}_{2}$ response test measurements offers moderate accuracy. ${ }^{14,15}$ Although of value for investigation of respiratory drive, this test is exposed to an intrinsic variability due to many reasons, such as the large day-to-day intraindividual variation in breathing pattern parameters. However, the reproducibility of the test, which has been analyzed in our study, shows good precision, which may provide reliable results on the effects of hyperoxia.

Finally, we measured $\dot{\mathrm{V}}_{\mathrm{E}}$ and $\mathrm{P}_{0.1}$ with a built-in ventilator function instead of the conventional method. This could overestimate high $\mathrm{P}_{0.1}$ values or underestimate low $\mathrm{P}_{0.1}$ values. ${ }^{27}$

Overall, our study shows the presence of hyperoxiainduced hypercapnia in normoxic, intubated COPD subjects with low inspiratory assistance and recovering from an exacerbation. According to our results, in this situation, a damped respiratory drive does not seem to be the major mechanism responsible for hyperoxia-induced hypercapnia. It most likely ultimately depends more on increased dead space, worsening ventilation-perfusion distribution, or the Haldane effect.

\section{Conclusions}

In summary, in normoxic subjects with COPD exacerbation during weaning from mechanical ventilation, hyperoxia does not seem to modify significantly the central respiratory drive or the ventilatory response to hypercapnia. Nonetheless, hyperoxia is followed by a 


\section{REsPiRATORY DRIVE AND HyPEROXIA-INDUCED HyPERCAPNIA}

slight increase in $\mathrm{P}_{\mathrm{aCO}}$, probably due to alterations in ventilation/perfusion matching and the Haldane effect.

\section{REFERENCES}

1. Prime FJ, Westlake EK. The respiratory response to $\mathrm{CO}_{2}$ in emphysema. Clin Sci 1954;13(3):321-332.

2. Campbell EJ. Respiratory failure: the relation between oxygen concentrations of inspired air and arterial blood. Lancet 1960;2(7140):10-11.

3. Aubier M, Murciano D, Fournier M, Milic-Emili J, Pariente R, Derenne JP. Central respiratory drive in acute respiratory failure of patients with chronic obstructive pulmonary disease. Am Rev Respir Dis 1980;122(2):191-199.

4. Aubier M, Murciano D, Milic-Emili J, Touaty E, Daghfous J, Pariente R, Derenne JP. Effects of the administration of $\mathrm{O}_{2}$ on ventilation and blood gases in patients with chronic obstructive pulmonary disease during acute respiratory failure. Am Rev Respir Dis 1980;122(5):747-754.

5. Sassoon CS, Hassell KT, Mahutte CK. Hyperoxic-induced hypercapnia in stable chronic obstructive pulmonary disease. Am Rev Respir Dis 1987;135(4):907-911.

6. Robinson TD, Freiberg DB, Regnis JA, Young IH. The role of hypoventilation and ventilation-perfusion redistribution in oxygeninduced hypercapnia during acute exacerbations of chronic obstructive pulmonary disease. Am J Respir Crit Care Med 2000;161(5): 1524-1529.

7. Dunn WF, Nelson SB, Hubmayr RD. Oxygen-induced hypercarbia in obstructive pulmonary disease. Am Rev Respir Dis 1991;144(3 Pt 1):526-530.

8. Dick CR, Liu Z, Sassoon CS, Berry RB, Mahutte CK. $\mathrm{O}_{2}$-induced change in ventilation and ventilatory drive in COPD. Am J Respir Crit Care Med 1997;155(2):609-614.

9. Hanson CW 3rd, Marshall BE, Frasch HF, Marshall C. Causes of hypercarbia with oxygen therapy in patients with chronic obstructive pulmonary disease. Crit Care Med 1996;24(1):23-28.

10. Santos C, Ferrer M, Roca J, Torres A, Hernández C, RodriguezRoisin R. Pulmonary gas exchange response to oxygen breathing in acute lung injury. Am J Respir Crit Care Med 2000;161(1):26-31.

11. Crossley DJ, McGuire GP, Barrow PM, Houston PL. Influence of inspired oxygen concentration on deadspace, respiratory drive, and $\mathrm{P}_{\mathrm{aCO}}$ in intubated patients with chronic obstructive pulmonary disease. Crit Care Med 1997;25(9):1522-1526.

12. Whitelaw WA, Derenne JP, Milic-Emili J. Occlusion pressure as a measure of respiratory center output in conscious man. Respir Physiol 1975;23(2):181-199.
13. Fernández R, Cabrera J, Calaf N, Benito $\mathrm{S}$. $\mathrm{P}_{0.1} / \mathrm{P}_{\mathrm{IMax}}$ : an index for assessing respiratory capacity in acute respiratory failure. Intensive Care Med 1990;16(3):175-179.

14. Sahn SA, Zwillich CW, Dick N, McCullough RE, Lakshminarayan S, Weil JV. Variability of ventilatory responses to hypoxia and hypercapnia. J Appl Physiol 1977;43(6):1019-1025.

15. Lederer DH, Altose MD, Kelsen SG, Cherniack NS. Comparison of occlusion pressure and ventilatory responses. Thorax 1977;32(2): 212-220.

16. Boles JM, Bion J, Connors A, Herridge M, Marsh B, Melot C, et al Weaning from mechanical ventilation. Eur Respir J 2007;29(5):10331056.

17. Sidney DA, Poon CS. Ventilatory responses to dead space and $\mathrm{CO}_{2}$ breathing under inspiratory resistive load. J Appl Physiol 1995;78(2): 555-561.

18. Ranieri VM, Giuliani R, Mascia L, Grasso S, Petruzzelli V, Puntillo $\mathrm{N}$, et al. Patient-ventilator interaction during acute hypercapnia: pressure-support vs. proportional-assist ventilation. J Appl Physiol 1996;81(1):426-436.

19. Raurich JM, Rialp G, Ibáñez J, Campillo C, Ayestarán I, Blanco C. Hypercapnia test as a predictor of success in spontaneous breathing trials and extubation. Respir Care 2008;53(8):1012-1018.

20. Kuhlen R, Hausmann S, Pappert D, Slama K, Rossaint R, Falke K. A new method for $\mathrm{P}_{0.1}$ measurement using standard respiratory equipment. Intensive Care Med 1995;21(7):554-560.

21. Fernandez R, Raurich JM, Mut T, Blanco J, Santos A, Villagra A. Extubation failure: diagnostic value of occlusion pressure $\left(\mathrm{P}_{0.1}\right)$ and $\mathrm{P}_{0.1}$-derived parameters. Intensive Care Med 2004;30(2):234-240.

22. Alberti A, Gallo F, Fongaro A, Valenti S, Rossi A. $P_{0.1}$ is a useful parameter in setting the level of pressure support ventilation. Intensive Care Med 1995;21(7):547-553.

23. Brochard L, Rua F, Lorino H, Lemaire F, Harf A. Inspiratory pressure support compensates for the additional work of breathing caused by the endotracheal tube. Anesthesiology 1991;75(5):739-745.

24. Mehta S, Nelson DL, Klinger JR, Buczko GB, Levy MM. Prediction of post-extubation work of breathing. Crit Care Med 2000;28(5): $1341-1346$

25. Luft UC, Mostyn EM, Loeppky JA, Venters MD. Contribution of the Haldane effect to the rise of arterial $\mathrm{P}_{\mathrm{CO}_{2}}$ in hypoxic patients breathing oxygen. Crit Care Med 1981;9(1):32-37.

26. Lopez-Majano V, Dutton RE. Regulation of respiration during oxygen breathing in chronic obstructive lung disease. Am Rev Respir Dis 1973;108(2):232-240.

27. Subirana M, Irrazábal C, Bak E, Jara F, Mancebo J. Assessment of occlusion pressure measurement using standard respiratory equipment of Evita ventilators. Med Intensiva 1997;21(8):305-310.

This article is approved for Continuing Respiratory Care Education credit. For information and to obtain your CRCE

(free to AARC members) visit www.rcjournal.com 